\title{
Investigation of Sand Behaviour under Cyclic Loading
}

Investigation of Sand Behaviour under Cyclic Loading

Received

Siddeshwaran Parthiban, Gediminas Stelmokaitis, Viktoras Doroševas* 2016/12/08

Kaunas University of Technology, Faculty of Civil Engineering and Architecture

Studentu str. 48, LT-51367 Kaunas, Lithuania

Accepted after revision 2017/05/03

*Corresponding author: viktoras.dorosevas@ktu.lt

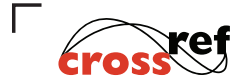

http://dx.doi.org/10.5755/j01.sace.19.2.17223

One of the challenges in geotechnical engineering is how to evaluate sandy soil behaviour under cycling loading. This challenge has led to several research projects regarding cyclic loading. However, due to the complexity of the loading and the effects hereof, no standardized method for taking into consideration the cyclic loading has been made yet. Therefore, the topic of cyclic loading still needs more investigation. Proposed study finds an alternative approach to determine quantifiable methods for determination of cyclic load parameters like compressibility and shear modulus of sand, secant modulus, damping coefficients for various applied frequencies and account for shear strength of sands in worst case scenarios. It is also proposed the method, how to determine liquefaction potential and critical void ratios for various reconstituted sand mixtures in a laboratory setting.

The purpose of investigation is to describe how the sandy soil behaves when it is subjected to cyclic loading. Cyclic loading can be caused by environmental loads by wind, transport systems, earthquakes and even human induced loads like explosions. This form of loading will have influence on soil properties such as soil stiffness, shear strength, and void ratio.

Two different well graded sands are characterized and studied under static and dynamic loading and settlement studies are also performed on model footing being loaded on these sand samples. Frequency response of sands are also studied using shaking table subjected to frequency range of $10-50 \mathrm{~Hz}$ and determined its influence on strength parameters of soil.

Keywords: sand, soil, behaviour, cyclic load, compressibility, settlement, strength.

Sand is a granular material in nature and applied load is being transmitted in sand via grain to grain contacts. The cyclic stress-strain behaviour of sand therefore depends on the physiochemical and geomorphological characteristics of the grain contacts prior and during the cyclic shearing, and on the magnitude and direction of the contact forces. Microscopic aspects of the sand structure and its behaviour depends on the properties of grain contacts and their changes due to the external loading is a complex subject which is summarized to different extents in a number of geotechnical textbooks. Among them are books, for example (Mitchell, Soga, 2005), where the subject is described systematically and in considerable depth. Based on the synthesis of relevant studies, also including the pioneering work of Terzaghi, it was offered the description of sand microstructure that can be summarized as follows. The surface of sand grains is rough, with successions of nanoscale asperities and depressions. When the surfaces of adjacent grains are brought together by force, their contact is established through these asperities, which are subjected to very high stresses. The compressed asperities form the actual solid-to-solid contacts, which cumu-

\section{Introduction}

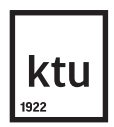

Journal of Sustainable Architecture and Civil Engineering Vol. 2 / No. 19 / 2017 pp. $57-64$

DOI 10.5755/j01.sace.19.2.17223 (C) Kaunas University of Technology 
lative area is just a small fraction of the total grain-to-grain contact surface. Due to the extreme stresses, the mineral material at and around the solid-to-solid contacts yields and undergoes plastic deformation which results in the chemical bond formation at the points of contacts.

The cohesive forces at such plastic junctions are the source of sand shear stiffness and frictional resistance, which magnitudes depend on the molecular structure and composition of contacting asperities. In addition to that, the grain surfaces are covered with a thin layer of adsorbed material from adjacent phases (water and/or air in the voids), but under high pressure the grain mineral at asperities penetrates through this film and forms the mineral solid-to-solid contacts. It is easy to comprehend that in such a sand structure, even at very small cyclic strains, the cyclic deformations and rubbing at and around the solid-to-solid contacts must modify the properties of the contacts in some manner, and that such changes must change the stiffness and elasticity moduli of the sand. In fact, this phenomenon has been recognized before by Drnevich and Richart in one of their studies on the cyclic behaviour of sand under small cyclic strains.

Evaluation of liquefaction resistance and earthquake-induced pore water pressure (PWP) in sands are a topic of considerable importance among the geotechnical engineers. Numerous researchers have investigated liquefaction potential of sand through the experimental (Di Prisco et al., 2000), numerical (Dafalias, Manzari, 2004) and empirical approaches (Modoni et al., 2011). Experimental investigations have constituted the basis of liquefaction studies and provided considerable insight into this problematic undrained behaviour of soils.

Methods

The sand soil is the object of research in this paper. Two sand samples A and B which has a particle grading of well graded (GW) are used and the particle size distribution is being plotted to differentiate various fractions of sand particle. These sands are subjected to static and cyclic loading. Settlement studies are performed on purpose to analyse the failure modes in dry state and saturated state.

\section{Particle Size Distribution}

The sands were characterised according to Eurocode 7 and subjected to all index properties and particle size distribution. The sand samples were free of any organic matter and had very small amount of fine content, less than $2 \%$ by mass. The sands grading results are shown in Fig. 1 and characteristics of the sand are given in Table 1.

Fig. 1

Particle size distribution

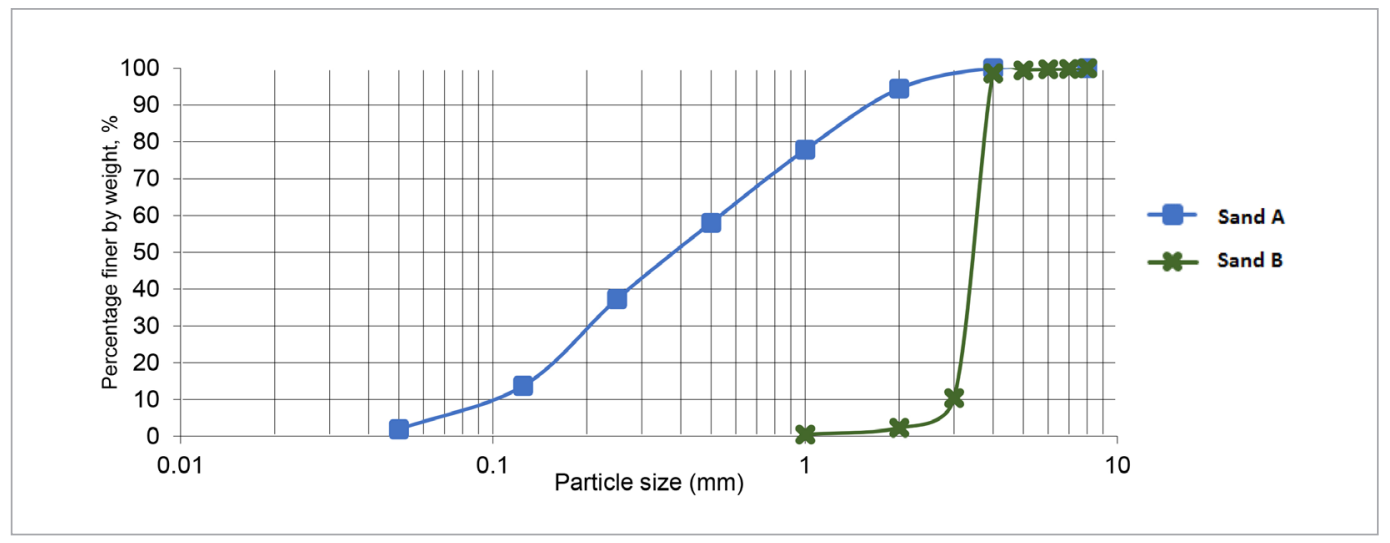

\section{Table 1}

Index properties of sand samples

\begin{tabular}{cl|l}
\multicolumn{1}{c|}{ Sand $\mathrm{A}$} & \multicolumn{1}{c}{ Sand $\mathrm{B}$} \\
\hline 1. & Specific Gravity -2.62 & Specific Gravity -2.58 \\
\hline 2. & Coefficient of uniformity $\mathrm{C}_{\mathrm{u}}-6$ & Coefficient of uniformity $\mathrm{C}_{\mathrm{u}}-6$ \\
\hline 3. & Coefficient of Curvature $\mathrm{C}_{\mathrm{c}}-2.4$ & Coefficient of Curvature $\mathrm{C}_{\mathrm{c}}-2.1$
\end{tabular}


The sands are classified as well graded sand-GW.

\section{Simple shear tests under statical and dynamic loads}

The mechanical properties of the soil are the most important ones for geotechnical engineers. Laboratory tests have been performed in order to determine the shear stress of failure, as well as its cohesion ( $c$ ) and angle of friction $(\varphi)$. The tests were performed under static conditions and by inducing vibrations on sand sample on purpose to determine the change of mechanical properties of sand affected by vibrations. The failure shear stress of sand with and without vibrations have been found using Field laboratory apparatus PLL-9.

Vibrations in soil can be generated from various sources, i.e. road traffic, pile driving, explosions and construction equipment. These sources generate waves with frequency up to $70 \mathrm{~Hz}$. The specimens of sand used in this testing were cylindrical shape of $56.5 \mathrm{~mm}$ diameter and $20 \mathrm{~mm}$ height. Shear tests on sand have been performed with three different normal stresses: $100 \mathrm{kPa}, 200 \mathrm{kPa}$ and $300 \mathrm{kPa}$ and placing the apparatus on laboratory shaking table that induces vibrations of $50 \mathrm{~Hz}$ frequency (Fig. 2). Horizontal load was increased with a step of $4.8 \mathrm{kPa}$ of shear stress on sand specimen until it reached limit state and failure shear stress. As it is known, the shear strength of soil can be expressed by Coulomb equation:

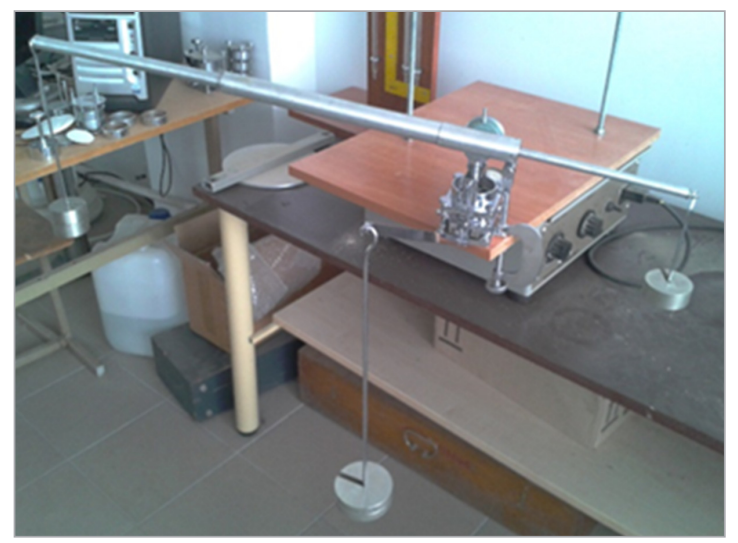

Fig. 2

Static and dynamic testing

$$
\tau_{f}=c+\sigma \tan \varphi
$$

where:

$\tau_{f}$ - failure shear stress; $c$ - cohesion;

$\sigma$-normal stress; $\varphi$ - internal angle of friction.

Shear tests on sands have been carried out under static conditions and with vibrations of $50 \mathrm{~Hz}$ frequency. Tests with $50 \mathrm{~Hz}$ vibrations were performed on laboratory shaking table (Fig. 2) and the sands were tested in dry state until failure.

\section{Settlement studies}

The sands were tested using a model footing on purpose to investigate the settlement in static conditions and loaded until general shear failure is obtained (Fig. 3).

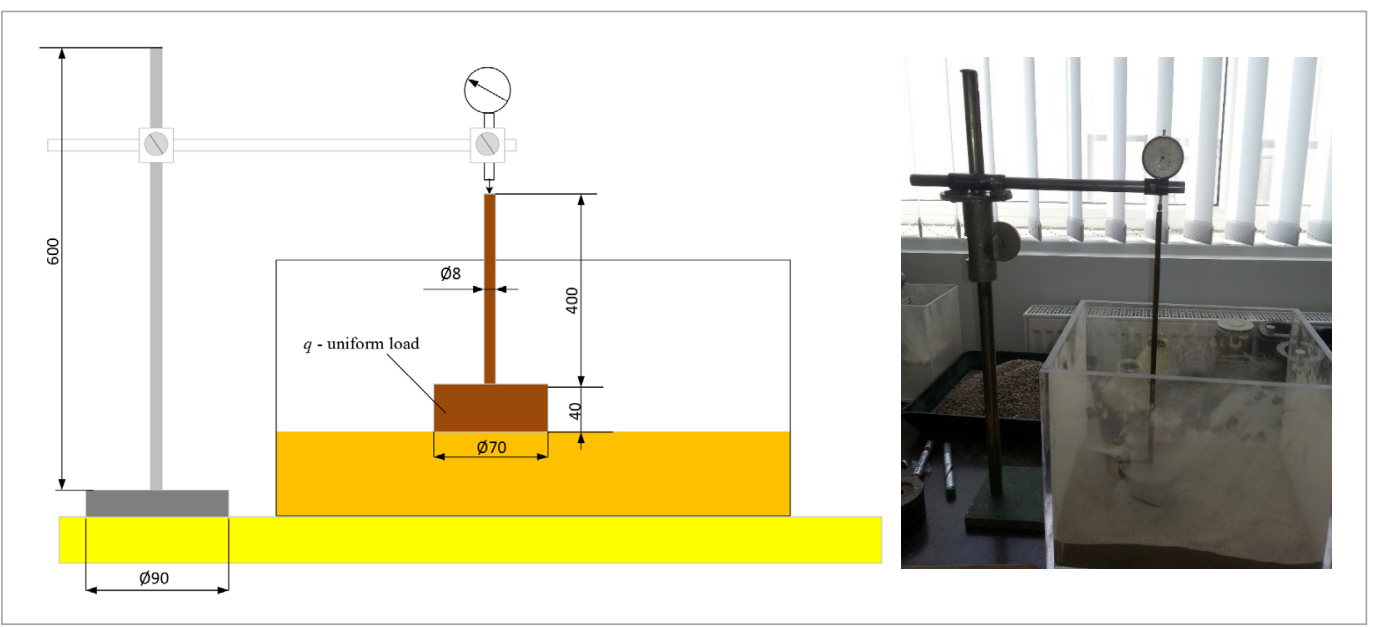


These studies were done to validate the scaling effect and check in which extent the experimental results correspond to analytical solution. Based on the theory of elasticity, the elastic settlement $s_{i}$ of a flexible footing, either rectangular of dimensions $L \times B(L>B)$ or circular of diameter $B$, is given by

$$
s=I_{s} \frac{q B\left(1-\mu^{2}\right)}{E}
$$
where:

$I_{s}$ - influence factor depending on the shape and L/B ratio; (for case $\mathrm{A}$ and $\mathrm{B} I_{s}=0.85$ ); $q$ - uniform loading; $E$ - modulus of elasticity; $\mu$ - Poisson's ratio.

For average settlement:

$s_{i}=0.926 s$

\section{Friction angle tests}

Friction angle tests on sand have been carried out with UVT-2 and UO (Fig. 4) under vibrations with $10 \mathrm{~Hz}, 2 \mathrm{~Hz}, 40 \mathrm{~Hz}$ and $50 \mathrm{~Hz}$ frequency. The vibrations were performed using frequency changing vibration table in Technological Systems Diagnostics Institute of Kaunas University of Technology (Fig. 5). The amplitude of vibrations in all tests was set to be $0.3 \mathrm{~mm}$.
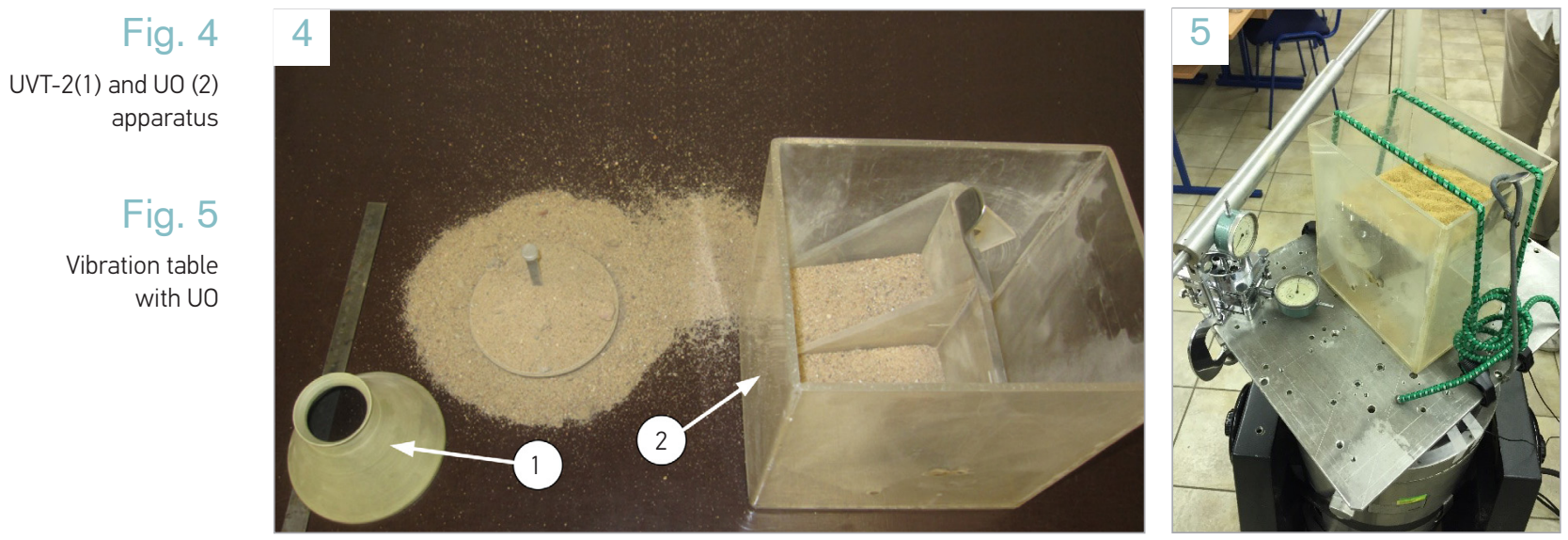

Results and

The results obtained during the direct shear test on sand A and B without and with vibration are illustrated in Fig. 6 and Fig. 7. The experiments show that vibrations had effect on cohesion parameters of sand. Cohesion of sand has decreased under vibrations of $50 \mathrm{~Hz}$ frequency and reduced the strength of sand calculating by Eq. (1), but the angle of friction remained the same.

The sands were tested using a model footing to investigate the settlement in static conditions. These studies were done to validate the scaling effect and check in which extent the experimental results correspond to analytical solution by Eqns. (2) and (3). The results obtained during the settlement test on sand A and B are illustrated in Fig. 8 and Fig. 9.

The experiments show that it is possible to use obtained empirical equations to calculate the average settlement under uniform load:

$s_{i}=a_{i} q$

(4) where:

$a_{i}$ - uniform load coefficient, $\frac{\mathrm{m}^{2}}{\mathrm{~N}} \mathrm{~mm}$. 


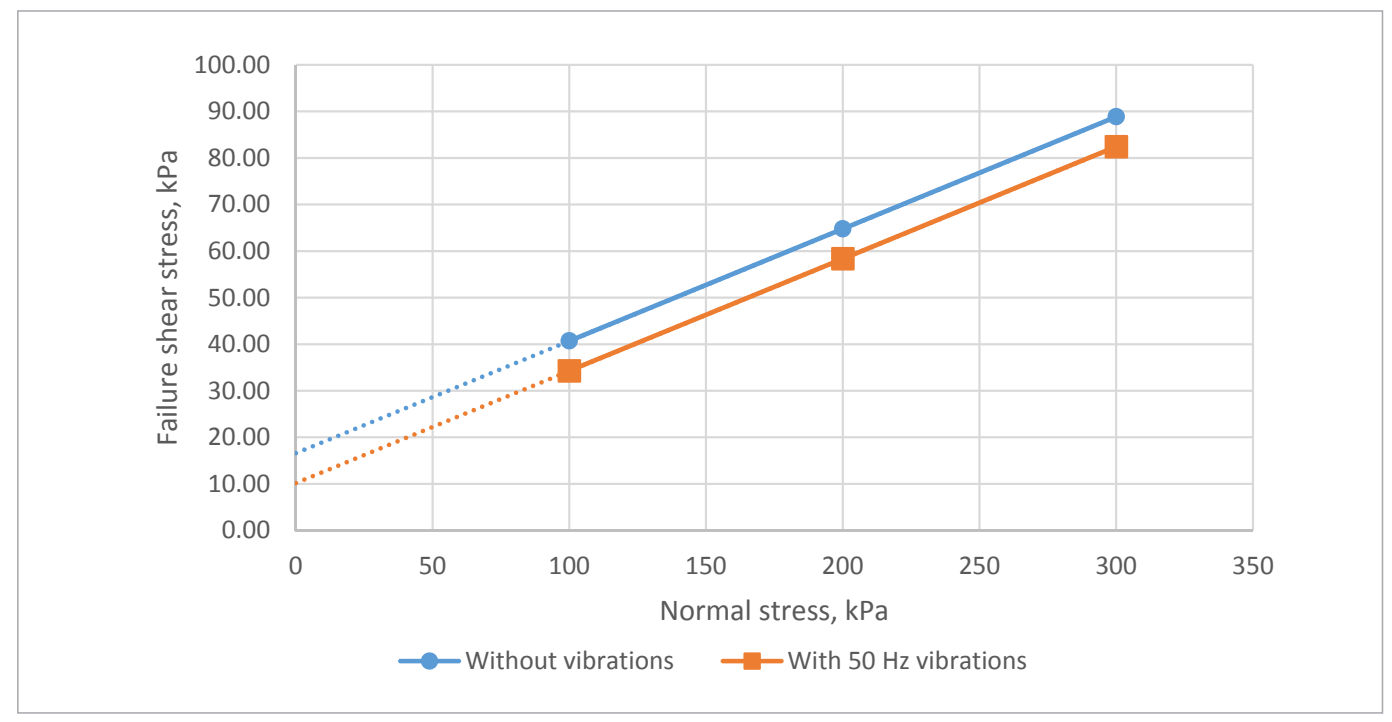

Fig. 6

Direct shear test on sand $A$

Fig. 7

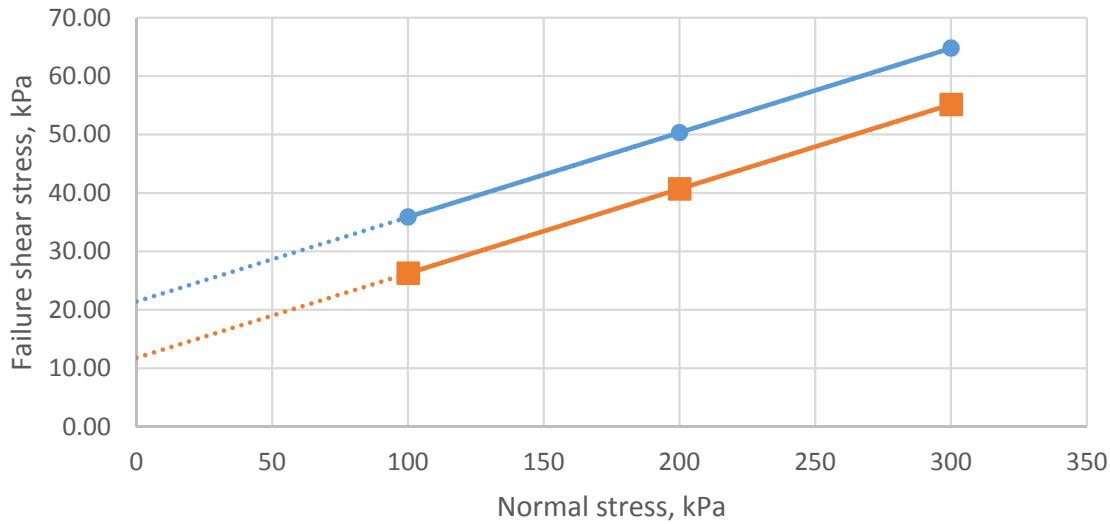

- Without vibrations $\quad-$-With $50 \mathrm{~Hz}$ vibrations

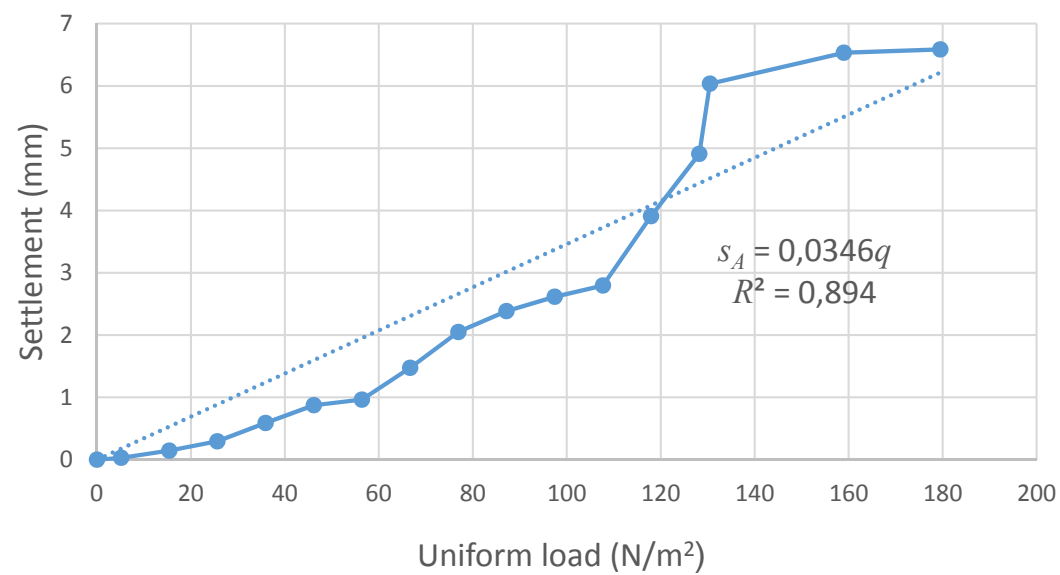

Fig. 8

Settlement test sand $A$

Direct shear test on sand $B$ 
Fig. 9

Settlement test sand $B$

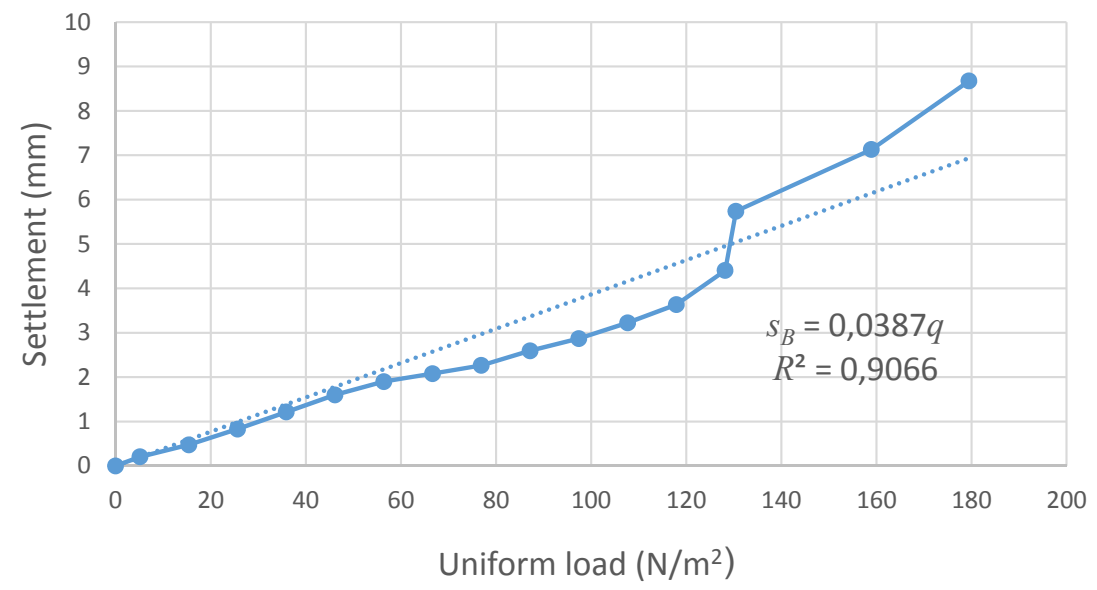

The uniform load coefficient depends on sand type, for example,

sand A $-a_{A}=0.0346 \frac{\mathrm{m}^{2}}{\mathrm{~N}} \mathrm{~mm}$ and

sand $B-a_{B}=0.0387 \frac{\mathrm{m}^{2}}{\mathrm{~N}} \mathrm{~mm}$.

The results calculated by Eq. (4) were compared to analytical solution which is defined by Eqns. (2) - (3) and are illustrated in Fig. 10 and Fig. 11.

The sand samples exhibit a good correlation between analytical and experimental values during settlement studies due to the scaling effect and particle sphericity which has a strong effect on shear strength during dynamic loading events.

The results obtained during the friction angle tests on loose sand under vibrations with $10 \mathrm{~Hz}$, $20 \mathrm{~Hz}, 40 \mathrm{~Hz}$ and $50 \mathrm{~Hz}$ frequency with UVT-2 and UO are illustrated in Fig. 12.

The experiments show that vibrations have effect on the angle of friction of sand slope. The angle of friction of slope sand has decreased under vibrations had increased from 10 to $50 \mathrm{~Hz}$ frequency.

\section{Fig. 10}

Comparison of experimental and analytical solution on sand $A$

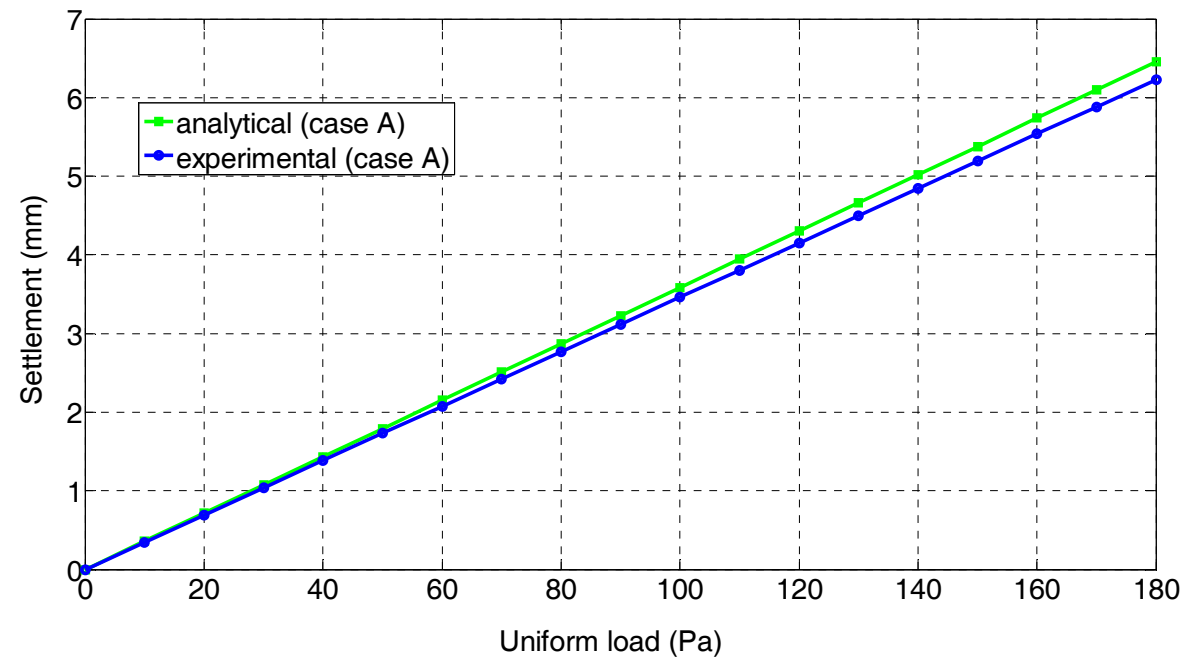




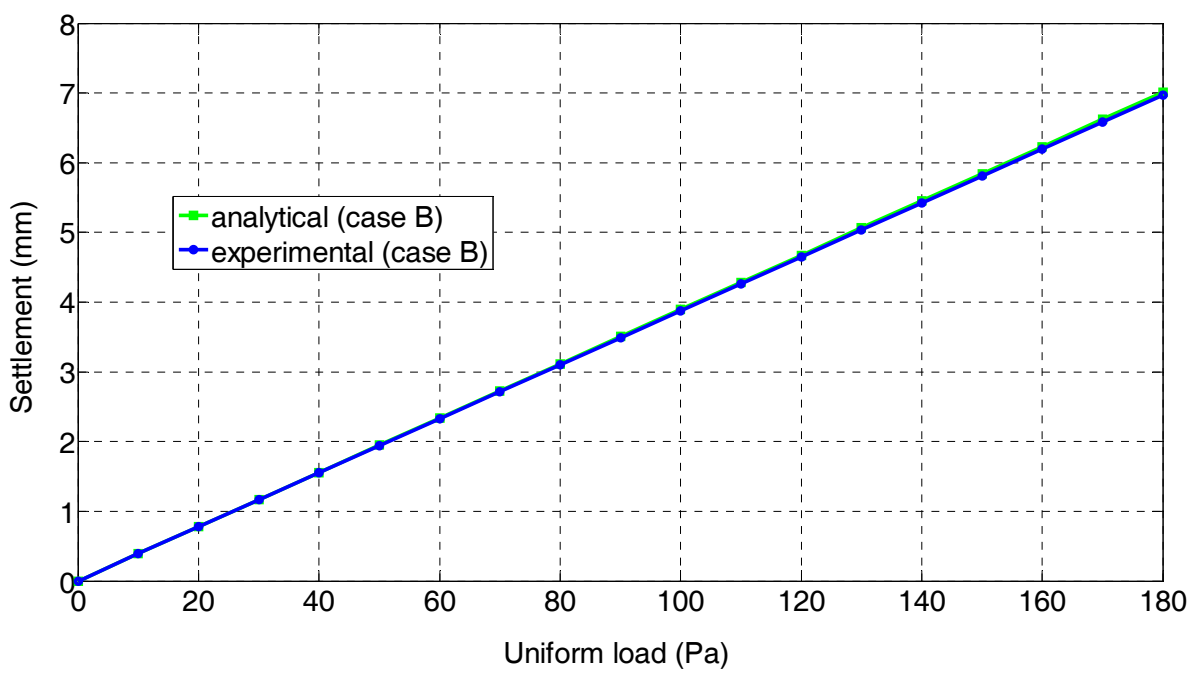

Fig. 11

Comparison of experimental and analytical solution on sand $B$

Fig. 12

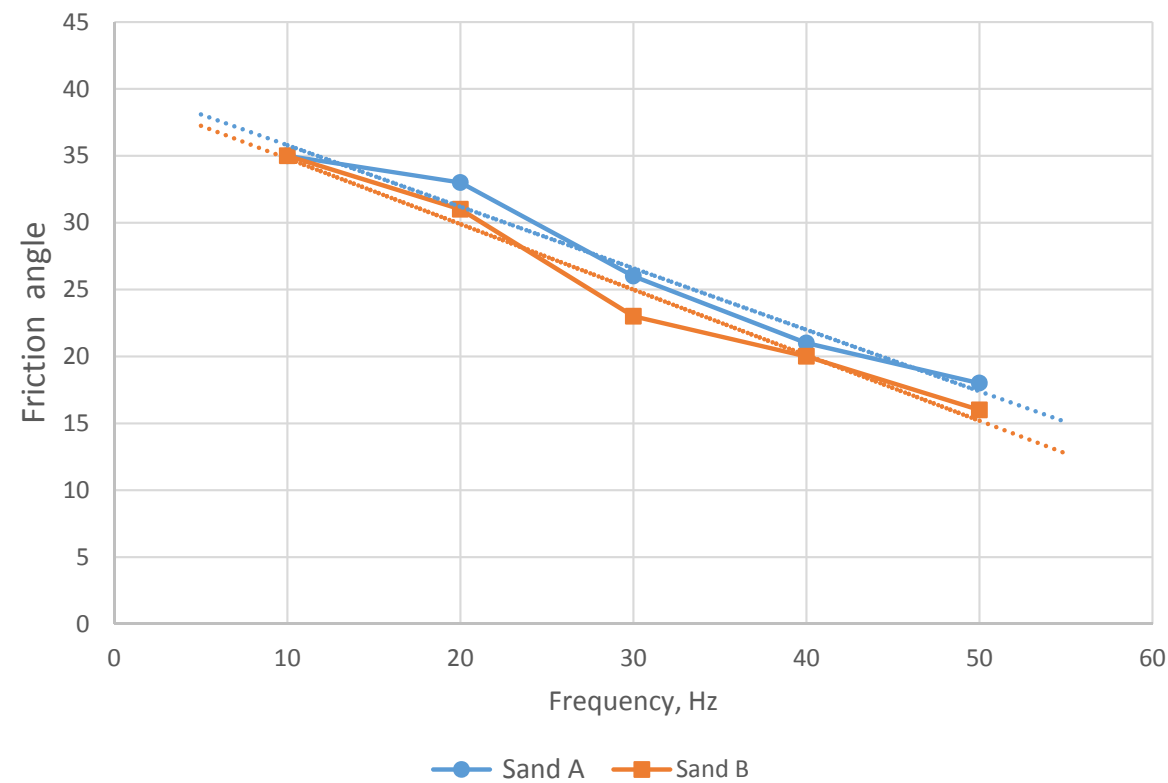

Friction angle on sand $A$ and $B$

Experimental analysis until $50 \mathrm{~Hz}$ of vibrations on sand showed that:

It has negative effect on mechanical properties of sand;

Conclusions

Sand affected by $50 \mathrm{~Hz}$ vibrations indicated that the strength of dense sand decreased because of decrease in the cohesion, and it is relative with the type of sand and frequency;

It is important to take such change into account in geotechnical engineering because the decrease of strength of sand can cause unpredicted foundation settlements and other problems.

Experimental analysis of settlements test on sand showed that:

Analytical and experimental values of settlement follow a similar trend and using the scaling effect it can be calculated empirical. 
The main strength parameter of sand (angle of friction) are also affected by vibrations. Experiments showed that:

- The angle of friction is hugely affected by different frequency of vibrations;

Under $50 \mathrm{~Hz}$ vibrations the angle of friction decreased by $47 \%$ while under low frequency vibrations $(10 \mathrm{~Hz})$ sand the angle of friction was equal to $35^{\circ}$. The angle of friction of sand slope has decreased under vibrations increase. It is important to take such change into account in geotechnical engineering.

\section{References}

Mitchell JK, Soga K. Fundamentals of soil behaviour. Hoboken, New Jersey: John Wiley \& Sons, Inc.; 2005. p. 577. Eurocode 7 - Geotechnical design - Part 2: Ground investigation and testing, EN 1997-2:2007/AC:2010.

Di Prisco C., Imposimato S., Vardoulakis I. Mechanical modelling of drained creep triaxial tests on loose sand, Géotechnique 50(1) (2000)73-82. https://doi. org/10.1680/geot.2000.50.1.73
Dafalias Y., Manzari M. Simple Plasticity Sand Model Accounting for Fabric Change Effects, J.Eng. Mech., 130(6) (2004) 622-634. https://doi.org/10.1061/ (ASCE)0733-9399(2004) 130:6(622)

Modoni G., Koseki J., Anh Dan L.Q. Cyclic stress strain response of compacted gravel, Géotechnique 61 (6) (2011) 473-485. https://doi.org/10.1680/ geot.7.00150

Acknow- The authors would like to acknowledge the support of Technological Systems Diagnostics Institute and Department of Building Structures of Kaunas University of Technology in conduct of this study. ledgment

\section{About the authors \\ SIDDESHWARAN PARTHIBAN}

Master's degree student

Kaunas University of Technology, Faculty of Civil Engineering and Architecture, Department of Building

Structures

\section{Main research area}

Soil investigations, SoilStructure interaction, Structural Dynamics

\section{Address}

Studentu St. 48, LT-51367,

Kaunas, Lithuania

E-mail: siddeshwaran. parthiban@ktu.edu

\section{GEDIMINAS STELMOKAITIS}

Assoc. Professor

Kaunas University of Technology, Faculty of Civil Engineering and Architecture, Department of Building Structures

\section{Main research area}

Soil investigations, soil mechanics, geology

\section{Address}

Studentu St. 48, LT-51367,

Kaunas, Lithuania

E-mail: gediminas.stelmokaitis@ ktu.edu

\section{VIKTORAS DOROŠEVAS}

\section{Professor}

Kaunas University of Technology, Faculty of Civil Engineering and Architecture, Department of Building Structures

\section{Main research area}

Mechanical systems, dynamics, analytical and numerical methods, mathematical model, theoretical mechanics, mechanics of loose materials, soil mechanics, diagnostics, transportation systems in buildings, damage of structures and soil, identification system and material state, monitoring. Analysis and synthesis of the reactions of structure to shock impact load and estimation

\section{Address}

Studentu St. 48-284, LT-51367,

Kaunas, Lithuania

E-mail: viktoras.dorosevas@ktu.lt 